\title{
Data insertion in volcanic ash cloud forecasting
}

\author{
Kate L. Wilkins ${ }^{1 *}$, Shona Mackie ${ }^{1}$, I. Matthew Watson ${ }^{1}$, Helen \\ N. Webster ${ }^{2}$, DAVID J. ThOMSON ${ }^{2}$, Helen F. DACre ${ }^{3}$ \\ 1 University of Bristol, 2 Met Office, Exeter, 3 University of Reading \\ *kate.wilkins@bristol.ac.uk
}

\begin{abstract}
During the eruption of Eyjafjallajökull in April and May 2010, the London Volcanic Ash Advisory Centre demonstrated the importance of infrared (IR) satellite imagery for monitoring volcanic ash and validating the Met Office operational model, NAME. This model is used to forecast ash dispersion and forms much of the basis of the advice given to civil aviation. NAME requires a source term describing the properties of the eruption plume at the volcanic source. Elements of the source term are often highly uncertain and significant effort has therefore been invested into the use of satellite observations of ash clouds to constrain them. This paper presents a data insertion method, where satellite observations of downwind ash clouds are used to create effective 'virtual sources' far from the vent. Uncertainty in the model output is known to increase over the duration of a model run, as inaccuracies in the source term, meteorological data and the parameterizations of the modelled processes accumulate. This new technique, where the dispersion model (DM) is 'reinitialized' part-way through a run, could go some way to addressing this.
\end{abstract}

\section{INTRODUCTION}

atellite imagery is an important tool for detecting and monitoring volcanic ash clouds. IR satellite sensors are used for imaging ash day and night and performing retrievals of the physical properties of ash clouds [e.g. Wen and Rose, 1994; Francis et al., 2012; Pavolonis et al., 2013]. We present a novel method to combine IR observations and dispersion modelling for volcanic ash forecasting, and give a brief overview of some of the current methods. Here, the term eruption plume is used to describe a column of ash erupting from the volcano vent. Ash which has been passively transported by wind is described as downwind or distal.
When using volcanic ash DMs such as the Numerical Atmospheric-dispersion Modelling Environment (NAME) [Jones et al., 2007], many of the eruption source parameters (ESP) contributing to the source term (e.g. eruption plume height, mass emission rate) need to be estimated, often with high uncertainty, which can cause large uncertainties in model output [Devenish et al., 2012a]. Furthermore, errors in the simulated ash cloud location in space and time can result from uncertainties in the driving meteorology [Eckhardt et al., 2008], which have been shown to cause cumulative uncertainties in model output [Dacre et al., 2011] and can lead to errors in calculated ash column loading (ACL).

Model validation $\mathcal{E}$ data assimilation 
Operationally, some of the effects of ESP uncertainty are addressed through validation of model output against remotely sensed and in-situ observations prior to a forecast being issued [Webster et al., 2012]. Millington et al. [2012] developed a method to enable like-withlike comparison of IR satellite imagery and DM output using the fast radiative transfer model RTTOV to simulate images from the Spinning Enhanced Visible/Infrared Imager (SEVIRI) sensor on-board the Meteosat Second Generation satellite.

Data assimilation (DA) is used to estimate the true state of a system where both model output and observations are uncertain. This can then be used as an initial state from which to produce a forecast for some later time. DA in this field has been approached a number of ways. Denlinger et al. [2012] presented a Bayesian method to forecast uncertainty in ash dispersion. A genetic algorithm variational approach is presented by Schmehl et al. [2011] to minimize differences between modelled and observed ash concentrations. Inversion modelling is a DA method that has been used to estimate optimized ESPs, for both volcanic ash [e.g. Stohl et al., 2011; Kristiansen et al., 2012] and $\mathrm{SO}_{2}$ [e.g. Eckhardt et al., 2008; Flemming and Inness, 2013; Boichu et al., 2014], using later observations to reduce ESP uncertainty and hence improve DM predictions.

The above methods have been shown to improve ESP estimation; however, even if the source term is known perfectly, uncertainties in model output can still increase with run time. A simple method is presented here using satellite observations to initialize DM simulations at a series of time-steps. This may halt the propagation of some uncertainty via sequential updates of the simulations instead of ESP correction, and requires little to no prior knowledge of the eruption source term.

\section{MetHODS}

The viability of using retrievals from IR satellite observations of downwind ash clouds to initialize NAME dispersion and sequentially update NAME output (data insertion) is examined. No uncertainty analysis has yet been undertaken; this is an initial investigation which assumes negligible uncertainty in both the model and observations (see section IV for a short discussion). We use ACL and ash cloud height $(\mathrm{ACH})$ estimates from the 13-14 May 2010 Eyjafjallajökull ash cloud retrieved from the SEVIRI sensor following the 1D-variational (1D-Var) method of Francis et al. [2012], and meteorological data from the global version of the Met Office Unified Model (MetUM).

Table1: Volcanic ash PSD used operationally in NAME and distal PSD based on Table 1 from Dacre et al. [2013], derived from FAAM observations on 14May 2010.

\begin{tabular}{ccc}
\hline Particle & \multicolumn{2}{c}{ Fraction of total mass } \\
\cline { 2 - 3 } diameter & $\begin{array}{c}\text { Operational } \\
(\mu \mathrm{m})\end{array}$ & $\begin{array}{c}\text { Measured distal } \\
\text { NAME }\end{array}$ \\
\hline $0.1-0.3$ & 0.001 & 0.000 \\
$0.3-1.0$ & 0.005 & 0.006 \\
$1.0-3.0$ & 0.050 & 0.235 \\
$3.0-10.0$ & 0.200 & 0.535 \\
$10.0-30.0$ & 0.700 & 0.224 \\
$30.0-100.0$ & 0.044 & 0.000 \\
\hline
\end{tabular}

\section{Data insertion}

Each pixel from the SEVIRI image identified as ash is treated as a source in NAME. Together they contribute to a 'virtual source' where they are released into the model atmosphere instantaneously.

The retrieval provides no information on the vertical structure of the ash, so the entire ash cloud is estimated to be $1 \& 2 \mathrm{~km}$ thick, based on UK Facility for Airborne Atmospheric Measurements (FAAM) BAe-146 aircraft lidar and Cloud and Aerosol Spectrometer (CAS) measurements on 14 May 2010 [Johnson et al., 2012; Marenco et al., 2011], with a normally distributed vertical ash profile. The ash concentrations are calculated using the retrieved ACLs and the estimated source volumes.

The particle size distribution (PSD) used operationally in NAME (Table 1) includes particle sizes outside the range detectable by SEVIRI ( 1-35 $\mu$ m diameter [Stohl et al., 2011]). Both the operational PSD and one based on the distal PSD from Table 1 in Dacre et al. [2013] 
derived from FAAM measurements, which is more representative of the SEVIRI detection thresholds, are used for the simulations. A time-series of simulations are then combined to produce a forecast. The presence of water in the atmosphere as clouds can obscure ash by overlying it, by ash particles becoming coated in ice, or where an ash cloud has a high water content [Rose et al., 1995], so by combining a series of model runs initialized using the observations, it is more likely that features obscured by atmospheric water in one image are captured in others and evolved with time in the dispersion model.

\section{RESULTS}

Fig. 1a) shows a SEVIRI 'DustRGB' false color composite image at 1315 UTC on 14 May 2010 where ash shows as a pink streak extending northwest from Scotland toward Iceland and as a yellow region west of Iceland [Devenish et al., 2012b], b) is a NAME simulation for that time using a source term based on the Met Office's "best guess" of the plume height, calculated eruption rate and the operational PSD in Table 1 [Webster et al., 2012], and c) is retrieved ACL. The data insertion forecast $d$ ) is a combination of the greatest ACL values (for each grid cell) of four NAME simulations ending at 1315 UTC 14 May, initialized using retrievals from 2115 UTC 13 May, 0115, 0515 \& 0915 UTC 14 May, assuming $1 \mathrm{~km}$ layer thickness and normal vertical distribution at the time of insertion. Both the "best guess" and data insertion simulations are in good agreement with the ash position in 1a \& c), however 1b) shows lower ACL over the northeast and north of Iceland and much higher values west of Iceland than either the retrieval or data insertion simulation.

Fig. 1d) shows a large patch of ash over Greenland which is not visible in 1c) nor in $1 b$ ). It is possible to make out a pink area in that region in 1a) which may be ash; there is a negative brightness temperature (BT) difference in this region of the image (BT at $10.8 \mu \mathrm{m}$ wavelength - BT at $12.0 \mu \mathrm{m}$ wavelength) [not shown] which could indicate the presence of ash, but it is not clearly distinguishable from background values. Fig. 13c) in Johnson et al. [2012] shows lidar and CAS derived ash concentration profiles for 14 May at $59.6^{\circ} \mathrm{N} 7.0^{\circ} \mathrm{W}$. The ash layer has a peak concentration at $\sim 800 \mathrm{\mu g} \mathrm{m}^{-3}$ and is $\sim 2 \mathrm{~km}$ thick extending from $\sim 5-7 \mathrm{~km}$ altitude.
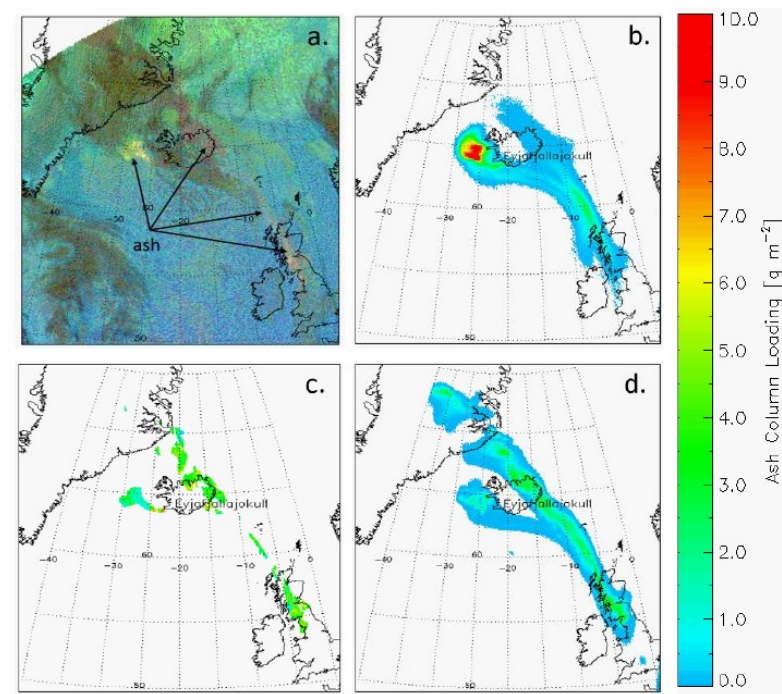

Figure 1: Eyjafjallajökull ash cloud at 1315 UTC 14 May 2010. a) SEVIRI 'DustRGB' false color composite image. b) "Best guess" NAME source term estimate (ACLs >10 $\mathrm{g} \mathrm{m}^{-2}$ shown as $10 \mathrm{~g} \mathrm{~m}^{-2}$ ). c) $1 D$-Var ACL retrieval. d) Data insertion forecast. Only ACLs $>0.01 \mathrm{~g}$ $m^{-2}$ shown in $1 b \mathcal{E} d$, color bar is for $1 b-d$.

Fig. 2 shows "best guess" and data insertion (1 \& $2 \mathrm{~km}$ ) modelled profiles for the same location at 1315 UTC using both PSDs in Table 1 , and a shaded region showing the approximate extent of the observed ash layer shown in Johnson et al. [2012]. All of the modelled peak concentrations are in reasonable agreement with the measurementderived profiles, with those from the data insertion runs slightly higher. These layers are also $\sim 2 \mathrm{~km}$ below the measured altitude (at a concentration of $200 \mu \mathrm{g} \mathrm{m}^{-3}$ ), possibly reflecting an underestimation of heights in the 1D-Var retrieval. However, the thickness of these layers is $2-3 \mathrm{~km}$ and therefore in better agreement than the "best guess" source term estimate, which is $\sim 4 \mathrm{~km}$. 


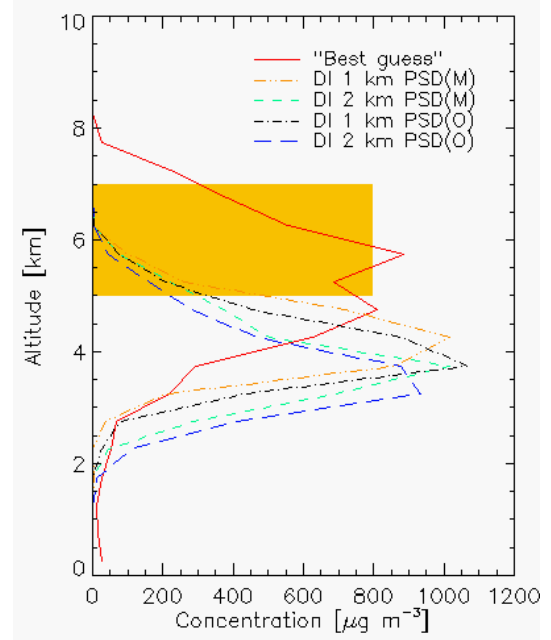

Figure 2: Ash concentration profiles for 1315 UTC 14 May at $59.6^{\circ} \mathrm{N} 7.0^{\circ} \mathrm{W}$. The solid line is the "best guess" NAME source term estimate. Other lines are the data insertion (DI) method assuming 1 and $2 \mathrm{~km}$ thick ash layers using the measured distal (M) and operational $(O)$ PSDs shown in Table 1. The line "DI $1 \mathrm{~km}$ PSD (M)" is from Fig. 1d). The filled box shows the approximate observed concentration profile from Fig. 13c) in Johnson et al. [2012].

\section{DiSCUSSION}

By assuming that the ash forms a single 1-2 km thick layer distributed normally in the vertical, potential multi-layered ash clouds are ignored. Also, ash particles with sizes outside the SEVIRI detection range and ash obscured by overlying meteorological cloud for long time periods may not be included in the 'virtual source'. Therefore the data insertion method may produce less conservative forecasts than where the ash is initialized at the eruption plume. However, the vertical depth and distribution of the ash layer can be updated according to observations from satellite-based lidar (e.g. CALIOP) or research flights when they become available. These observations could also be used to validate the 1D-Var height estimates, which correspond to the height of radiative emission and therefore may be below the top of the ash cloud for a sparse cloud [Francis et al., 2012].
Evaluation of both model and observation accuracy is challenging as neither constitute the "truth"; the model is not a true representation of reality and in cases of disagreement it is therefore unclear which is correct. A more sophisticated implementation of this scheme could address this by implementing weights that account for the model and observation uncertainties specific to each model and observation location. For historical events, epistemic uncertainties could be informed using other available data, but in an operational setting when a DM must be run in near-real time, these may be unknown or poorly constrained. Uncertainties can be provided by the 1D-Var scheme, however accurate and reliable model uncertainties are more difficult to calculate. There is ongoing work in the dispersion modelling community to better characterize and quantify both model and observational uncertainty and future work will focus on including these.

In this paper a novel approach using the Met Office NAME DM and a 1D-Var IR satellite retrieval algorithm is suggested. A data insertion method is shown, using retrievals of downwind ash clouds within NAME as a snapshot from which to reinitialize ash dispersion instead of using the eruption source term. An example shows good agreement with ash position and column loading from satellite imagery, and layer thickness and peak concentrations agree reasonably with aircraft measurements, however layer altitude estimates are too low. A more sophisticated sequential update assimilation scheme should allow known uncertainties in the model and observations to be well characterized and tracked throughout to provide a forecast indicating uncertainty.

\section{ACKNOWLEDGEMENTS}

This work was supported by the Natural Environment Research Council [Consortium on Risk in the Environment: Diagnostics, Integration, Benchmarking, Learning and Elicitation (CREDIBLE) and Cooperative Awards in Science \& Technology (CASE, Met 
Office); grant ref. NE/J017450/1]. Thanks to the reviewers for their helpful comments, to Pete Francis for providing code for the 1D-Var method and great help implementing it, Claire Witham, James Hocking (Met Office), and Natalie Harvey for helpful input. We acknowledge use of the NAME atmospheric dispersion model and associated NWP meteorological data sets made available to us by the Met Office, and EUMETSAT for the provision of SEVIRI data via the Earth Observation Portal.

\section{REFERENCES}

[Boichu et al., 2014] Boichu, M., Clarisse, L., et al. (2014). Improving volcanic sulur dioxide cloud dispersal forecasts by progressive assimilation of satellite observations. Geophys. Res. Lett., 41:2637-2643.

[Dacre et al., 2011] Dacre, H.F., Grant, A.L.M., et al. (2011). Evaluating the structure and magnitude of the ash plume during the initial phase of the 2010 Eyjafjallajökull eruption using lidar observations and NAME simulations. J. Geophys. Res., 116:D00U03, doi:10.1029/2011JD015608.

[Dacre et al., 2013] Dacre, H.F., Grant, A.L.M., et al. (2013). Aircraft observations and model simulations of concentration and particle size distribution in the Eyjafjallajökull volcanic ash cloud. Atmos. Chem. Phys., 13:1277-1291.

[Denlinger et al., 2012] Denlinger, R.P., Pavolonis, M.J., et al. (2012). A robust method to forecast volcanic ash clouds. J. Geophys. Res., 117:D13208, doi:10.1029/2012JD017732.

[Devenish et al., 2012a] Devenish, B.J., Thomson, D.J., et al. (2012a). A study of the arrival over the United Kingdom in April 2010 of the Eyjafjallajökull ash cloud using groundbased lidar and numerical simulations. Atmos. Environ., 48:152-164.

[Devenish et al., 2012b] Devenish, B. J., Francis, P. N., et al. (2012b). Sensitivity analysis of dispersion modeling of volcanic ash from
Eyjafjallajökull in May 2010. J. Geophys. Res., 117, D00U21, doi:10.1029/2011JD016782.

[Eckhardt et al., 2008] Eckhardt, S., Prata, A.J., et al. (2008). Estimation of the vertical profile of sulfur dioxide injection into the atmosphere by a volcanic eruption using satellite column measurements and inverse transport modeling. Atmos. Chem. Phys., 8:3881-3897.

[Flemming and Inness, 2013] Flemming, J. and Inness, A. (2013). Volcanic sulfur dioxide plume forecasts based on UV satellite retrievals for the 2011 Grímsvötn and the 2010 Eyjafjallajökull eruption. J. Geophys. Res. Atmos., 118:172-189.

[Francis et al., 2012] Francis, P.N., Cooke, M.C., et al. (2012). Retrieval of physical properties of volcanic ash using Meteosat: A case study from the 2010 Eyjafjallajökull eruption. J. Geophys. Res., 117:D00U09.

[Johnson et al., 2012] Johnson, B.T., Turnbull, K., et al. (2012). In situ observations of volcanic ash clouds from the FAAM aircraft during the eruption of Eyjafjallajökull in 2010. J. Geophys. Res., 117:D00U24.

[Jones et al., 2007] Jones, A. R., Thomson, D. J., et al. (2007). 'The U.K. Met Office's NextGeneration Atmospheric Dispersion Model, NAME III', in Borrego, C. \& Norman, A. -L., (Eds) Air Pollution Modeling and its Application XVII Proc. $27^{\text {th }}$ NATO/CCMS International Technical Meeting on Air Pollution Modelling and its Application, Springer, 580-589.

[Kristiansen et al., 2012] Kristiansen, N.I., Stohl, A., et al. (2012). Performance assessment of a volcanic ash transport model mini-ensemble used for inverse modeling of the 2010 Eyjafjallajökull eruption. J. Geophys. Res., 117:D00U11.

[Marenco et al., 2011] Marenco, F., Johnson, B.T., et al. (2011). Airborne lidar observations of the 2010 Eyjafjallajökull volcanic ash plume. J.

Geophys. Res., 116:D00U05, doi:10.1029/2011JD016396.

[Millington et al., 2012] Millington, S.C., Saunders, R.W., et al. (2012). Simulated 
volcanic ash imagery: A method to compare NAME ash concentration forecasts with SEVIRI imagery for the Eyjafjallajökull eruption in 2010. J. Geophys. Res., 117:D00U17.

[Pavolonis et al., 2013] Pavolonis, M.J., Heidinger, A.K., et al. (2013). Automated retrievals of volcanic ash and dust cloud properties from upwelling infrared measurements. J. Geophys. Res. Atmos., 118:1436-1458.

[Rose et al., 1995] Rose, W.I., Delene, D.J., et al. (1995). Ice in the 1994 Rabaul eruption cloud: implications for volcano hazard and atmospheric effects. Nature, 375:477-479.

[Schmehl et al., 2011] Schmehl, K.J., Haupt, S.E., et al. (2011). A Genetic Algorithm Variational Approach to Data Assimilation and Application to Volcanic Emissions. Pure Appl. Geophys., 169:519-537.

[Stohl et al., 2011] Stohl, A., Prata, A.J., et al. (2011). Determination of time- and heightresolved volcanic ash emissions and their use for quantitative ash dispersion modeling: the 2010 Eyjafjallajökull eruption. Atmos. Chem. Phys., 11:4333-4351, doi:10.5194/acp-11-43332011.

[Webster et al., 2012] Webster, H.N., Thomson, D.J., et al. (2012). Operational prediction of ash concentrations in the distal volcanic cloud from the 2010 Eyjafjallajökull eruption. J. Geophys. Res., 117:D00U08, doi:10.1029/2011JD016790.

[Wen and Rose, 1994] Wen, S., and Rose, W.I. (1994). Retrieval of sizes and total masses of particles in volcanic clouds using AVHRR bands 4 and 5. J. Geophys. Res., 99:5421-5431. 